\title{
Endoscopic tissue shielding to prevent delayed perforation associated with endoscopic submucosal dissection for duodenal neoplasms
}

In Japan, endoscopic submucosal dissection (ESD) is increasingly performed for gastrointestinal neoplasms. However, ESD has not been widely applied to duodenal neoplasms. Postoperative delayed perforation occurs frequently because of exposure of pancreatic juice to the duodenum [1]. Regarding the closure technique after ESD, the usefulness of clip closure has been reported [2], but we encountered many cases of difficult clip closure for large mucosal defects. We considered that polyglycolic acid (PGA) sheets (Neoveil; Gunze Co., Kyoto, Japan) and fibrin glue (Beriplast P combi-set; CSL Behring Pharma, Tokyo, Japan) might be useful. The tumor in this case - a Ila lesion, approximately $2 \mathrm{~cm}$ in diameter - was located in the inferior duodenal angulus. The lesion was resected by employing ESD ( $\bullet$ Fig. 1a). The ulcer was covered with pieces of PGA sheet, fixed in place with fibrin glue ( $\bullet$ Fig. 1 b, c). No postoperative delayed perforation occurred, and the PGA sheets were still attached to the ulcer at 3 weeks after treatment ( $\bullet$ Fig. 1 d).

The only tools used in this method are biopsy forceps and two spray tubes. The sheet delivery method is also simple: a PGA sheet is cut to about $15 \times 5 \mathrm{~mm}$ ( Fig.2a,b) and delivered to the ulcer. The base of ulcer can be entirely covered by applying several sheets, followed by spraying fibrinogen through a spray tube to adhere the sheets to the ulcer, and then spraying thrombin through another spray tube.

This method has the following three advantages. First, it is simple compared with clip closure of large mucosal defects. Secondly, the PGA sheet and fibrin glue are spontaneously absorbed within 4-15 weeks. Thirdly, since PGA sheets and fibrin glue have been applied in many fields of surgery $[3,4]$, the safety level may be high.

Endoscopy_UCTN_Code_TTT_1AO_2AC
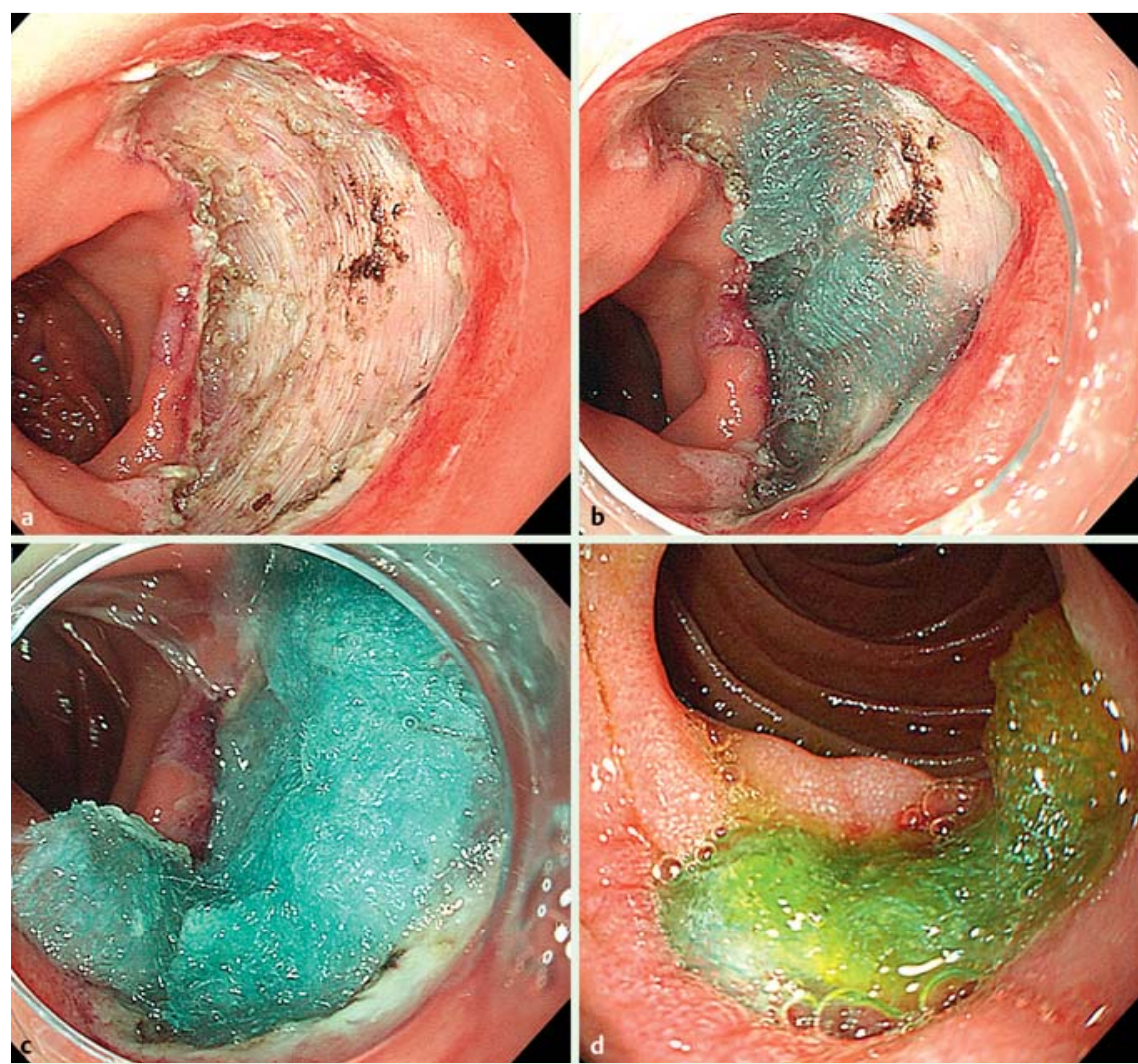

Fig. 1 Endoscopic tissue-shielding method using polyglycolic acid (PGA) sheets and fibrin glue. a Endoscopic view of an artificial duodenal ulcer immediately after endoscopic submucosal dissection (ESD). $\mathbf{b}$ The pieces of PGA sheet were delivered to the ulcer sheet by sheet. $\mathbf{c}$ The ulcer was entirely covered with PGA sheets, fixed in place with fibrin glue. $\mathbf{d}$ Endoscopic view 3 weeks after ESD, with the PGA sheets still adhering to the base of the ulcer.
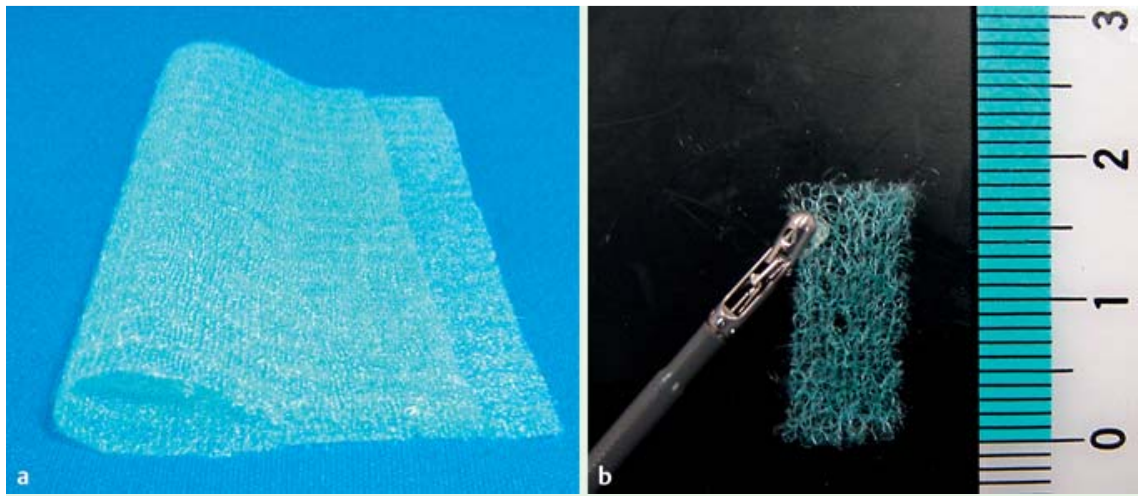

Fig. 2 a Polyglycolic acid (PGA) sheet $(100 \times 50 \mathrm{~mm})$. b The PGA sheet was cut to about $15 \times 5 \mathrm{~mm}$ and held with biopsy forceps with the hole-cap off to be delivered to the base of the ulcer. 
K. Takimoto', T. Toyonaga ${ }^{2}$, K. Matsuyama ${ }^{1}$

${ }^{1}$ Department of Gastroenterology, Takeda General Hospital, Kyoto, Japan

2 Department of Endoscopy, Kobe University Hospital, Hyogo, Japan

\section{References}

1 Ono $\mathrm{H}$, Nonaka $\mathrm{S}$, Uedo $\mathrm{N}$ et al. Clinical issues of duodenal EMR/ESD. Stomach and Intestine (Tokyo) 2011; 46: 1669-1677

2 Otake Y, Saito Y, Sakamoto T et al. New closure technique for large mucosal defects after endoscopic submucosal dissection of colorectal tumors (with video). Gastrointest Endosc 2012; 75: 663-667

3 Ueda $K$, Tanaka T, Hayashi $M$ et al. Meshbased pneumostasis contributes to preserving gas exchange capacity and promoting rehabilitation after lung resection. J Surg Res 2011; 167: e71 - e75

4 Uemura K, Murakami Y, Hayashidani Y et al. Combination of polyglicolic acid felt and fibrin glue for prevention of pancreatic fistula following pancreaticoduodenectomy. Hepatogastroenterology 2009; 56: 1538 1541

\section{Bibliography}

Dol http://dx.doi.org/

10.1055/s-0032-1325739

Endoscopy 2012; 44: E414-E415

(c) Georg Thieme Verlag KG

Stuttgart · New York

ISSN 0013-726X

\section{Corresponding author}

K. Takimoto, MD

Department of Gastroenterology

Takeda General Hospital

28-1, Ishida Moriminami-cho

Fushimi-ku

Kyoto 601-1495

Japan

Fax: +81-75-5718877

k-takimoto-kengo-1209-1209@y8.dion.ne.jp 